\title{
Treating Radiculopathy with an Indwelling Epidural Catheter and Infusion Pump
}

\author{
Kevin Pauza, MD, Michael Shapiro, MD, Aaron Calodney, MD, Sejong Bae, PhD, and Karan P. Singh, PhD
}

Background: For the purpose of reducing inflammation causing radiculopathy, lumbar transforaminal and interlaminar epidural injections deliver corticosteroid to the vicinity of the spinal nerve, nerve roots, and intervertebral disc. Although acceptable, the efficacy of transforaminal injections is limited and variable. An indwelling epidural catheter offers the distinct advantages of delivering greater concentrations of corticosteroid directly to the site of pathology, over an extended duration. This extended exposure to corticosteroid may benefit the site of pathology.

Objective: To evaluate the safety and efficacy of corticosteroid administered through a disposable indwelling epidural catheter and infusion pump to treat pain and dysfunction caused by lumbosacral radiculopathy.

Study Design: A pilot investigation

The first description of an "epidural" injection of corticosteroid described delivery through the S-1 posterior sacral foramen (1), which ultimately became the preferred method of treatment (29). Subsequently, this practice style slowly changed to bias epidural injections utilizing the caudal and interlaminar approaches (10-15). Subsequent reviews of the initial investigations (16-19), and comparisons to more recent controlled trials, revealed that epidural corticoste-

From: Texas Spine and Joint Hospital Tyler, TX; Tahoe Spine Center Incline Village, NV; and Department of Biostatistics, School of Public Health, University of North Texas, Fort Worth, TX.

Address Correspondence:

Michael Shapiro, MD, Tahoe Spine Center, 889 Alder Avenue \#303, Incline Village, NV 89451

E-mail: MikeShapiroMD@aol.com

Disclaimer: There was no external funding in preparation of this manuscript.

Conflict of Interest: Michael L. Shapiro, MD, is the inventor and owner of Infusion Catheter Epidural.

Manuscript received on 4/25/2005

Revision submitted on 6/15/2005

Accepted for publication on 6/21/2005 consisting of a prospective consecutive series of 10 patients, conducted in a specialty hospital.

Methods: An indwelling epidural catheter dispensed corticosteroid into the epidural space at the suspect level of pathology. The catheter was attached to an external, lightweight, spring-pressurized, and disposable reservoir pump holding $8.0 \mathrm{mg}$ dexamethasone diluted with bacteriostatic normal saline to a total volume of $72 \mathrm{ml}$. After each patient's hospital discharge, the medication was administered into the epidural space at a rate of $1 \mathrm{ml}$ per hour over a 72-hour period. Follow-up at six weeks was achieved in 100\% of the patients.

Outcome measures: The outcome measures, recorded at pre-treatment and six weeks post-treatment were assessed using: the Visual Analog Scale (VAS); MOS 36-
Item Short-Form Health Survey (SF-36); Pain Symptoms Survey; Oswestry Disability Index; Beck Inventory; Work History Survey; Work Index; Expectations Met Survey; Activities of Daily Living Form; and the Satisfaction With Treatment Form.

Results: There was no patient morbidity or mortality associated with this treatment, and patients, on average, experienced decreased pain levels after treatment. Mean delta VAS improvement was $4.1(\mathrm{SD}=2.6, \mathrm{R}$ $=-9.6$ to +1.5$)$. The mean percent improvement was $46.7 \%$.

Conclusions: Safe and effective treatment of lower extremity radiculopathy symptoms may be obtained with this new method.

Keywords: Lumbar spine, radiculopathy, indwelling epidural catheter, pump, corticosteroid

roids administered through interlaminar and caudal routes were less effective than initially claimed.

Investigators suggested that epidural corticosteroids might possess greater efficacy if they were delivered in a more exact fashion to the presumed site of pathology (20-23). Therefore, over time, transforaminal injections of corticosteroid evolved as the preferred route to treat radicular pain. This practice was kindled by reports of successful outcomes in observational studies, and later by the results of controlled trials.

These observations, coupled with the desire for increased efficacy, causes contemporary doctrine to favor administering medication directly onto the site of pathology by the transforaminal approach instead of the interlaminar or caudal approach (24-27). Unfortunately, because the corticosteroid is typically administered as a single bolus, both the maximum allowable dose and the duration of exposure to the medication remain limited.
Experimental evidence suggests that inflammatory processes cause the symptoms patients experience when lumbar spinal nerves and nerve roots are affected by intervertebral disc herniations (28-43). Corticosteroids suppress this inflammation, thus relieving the symptoms. Controlled trials (20-23) demonstrate greater efficacy when placing corticosteroid immediately proximal to the affected perineural tissue instead of in the general epidural area; thus logic dictates that directly bathing the affected spinal nerve, nerve root, and adjacent epidural tissue with corticosteroid over a prolonged period may serve to suppress inflammation and minimize symptoms.

Recall that injecting a single bolus of corticosteroid mandates that the maximum allowable dose, and the duration of exposure to the medication, both remain limited. To address that limitation, an indwelling epidural catheter offers the distinct advantage of delivering maximum concentrations of medication directly to the site of pathology, over an extended 
duration.

Because only one procedural encounter in a fluoroscopy facility is necessary for the performance of this procedure, it may offer cost effectiveness when compared with other contemporary treatments (32).

\section{M ethods}

\section{Patient Selection}

The study was approved by the institutional review board of the Texas Spine and Joint Hospital, Tyler, Texas. The objective was to test the efficacy and safety of an indwelling epidural catheter dispensing corticosteroid to treat radiculopathy. Between August 2004 and December 2004, patients for the study were recruited from the practice of the senior investigator. Interested patients who appeared eligible attended a face-to-face interview and physical examination to confirm their eligibility. Patients enrolled in this trial were to have experienced unilateral lower extremity radicular pain that occurred for longer than six week's duration and with intensity greater than six points out of 10 on the visual analogue scale (VAS). They must have had a positive straight leg raise test (Lasègue Sign) of between 20 degrees and 70 degrees from the horizontal plane. In some instances, electrodiagnostic signs of radiculopathy reinforced the diagnosis, but were not a prerequisite for inclusion. The target level to be treated was determined on the basis of the distribution of the patient's signs and symptoms, and on consideration of imaging studies, if these were available.

Other eligibility criteria were: patient age between 18 and 65 years; failure to improve following at least six weeks of non-operative care including anti-inflammatory and analgesic medications, and a physical therapy and/or home directed lumbar exercise program. Several subjects had failed to experience sustained relief with prior fluoroscopically-guided transforaminal injections of corticosteroid.

Exclusion criteria included: sequestered intervertebral disc herniations; concomitant cervical or thoracic pain greater than two out of 10 on the VAS; uncontrolled or acute medical illness; chronic severe conditions such as rheumatoid arthritis; ambulatory dysfunction; and unwillingness to consent to the study. Additionally, patients were also excluded if they had any of the following: a known anaphylactic reaction to contrast medium; demonstrated evidence of localized infection in the procedural field; a systemic infection; immunosuppression; bleeding diathesis or concurrent use of anticoagulants; pregnancy; or the potential for secondary gain including workmen's compensation, litigation, or disability.

\section{Equipment}

Components of the disposable indwelling epidural catheter and pump system used included: a $100 \mathrm{ml}$ medication reservoir with a carrying pouch and Velcro belt attachment; a 17-inch length of medication tubing; a 5 micron medication filter and flow regulator (Sgarlato Labs); an 18-gauge introducer needle; and a $100 \mathrm{~cm}, 20$-gauge radiopaque tipped medication catheter (Epimed).

\section{Technique}

After informed consent was obtained, the patient's posterior thoracic and lumbosacral skin was aseptically prepared and appropriately draped. The skin was anesthetized with $1.5 \%$ lidocaine, $1-5$ segments rostral to the suspect segment. Employing an interlaminar approach in an atypical cephalad to caudad trajectory, the tip of a 3.5-inch, 18-gauge introducer needle was directed into the epidural space with loss of resistance technique; appropriate epidural placement was confirmed by radiographic observation of injected radiopaque contrast medium (Isovue 300 ). A 20 -gauge spinal catheter was directed through the introducer needle and navigated in a caudal direction towards the suspect affected segment (Figure 1). Radiopaque contrast medium was again injected to confirm appropriate placement. Following confirmation, a bolus of $2 \mathrm{ml}$ of $1.5 \%$ lidocaine and $2 \mathrm{ml}$ of $4.0 \mathrm{mg} / \mathrm{ml}$ dexamethasone was injected through the catheter before securing it to the skin with an adhesive patch and connecting it to the infusion pump. Within the reservoir was $8.0 \mathrm{mg}$ dexamethasone diluted with bacteriostatic normal saline to a total volume of $72 \mathrm{~mL}$. The pump was pre-set to administer $1 \mathrm{ml}$ of injectate per hour over the ensuing 72-hour period, and subjects were discharged to home following 30 minutes of monitored recovery.

\section{Statistical Analysis}

The authors used the Statistical Analysis System statistical package (Ver- sion 8.2: SAS Institute, Cary, NC) for all statistical analyses. Patients served as their own control; a paired t-test was used to compare outcomes from baseline to a follow-up visit. The VAS, Oswestry, and SF36 scores from baseline to a follow-up visit were analyzed. Results are reported as the mean (standard deviation).

Results

Outcome tools were administered by a registered nurse and medical doctor and recorded at zero, three days, and six weeks. Tools included: the VAS (44-48); SF-36 (49-51); Pain Symptoms Survey; Oswestry Disability Index (52); Beck Inventory; Work History Survey; Work Index; Expectations Met Survey; Activities of Daily Living form; and the Satisfaction with Treatment forms.

For continuous variables, group means and standard deviations were determined and compared using a t-test. The primary objective of the study was to compare the improvement in pain and physical function before and after treatment. Secondary objectives included reporting the adverse event profile of an indwelling epidural catheter and functional outcomes as measured in the SF-36. For each patient, the percentage of pain relief at follow-up was calculated as the difference between their pain score from baseline, divided by their baseline score, and converted to a percentage.

Ten patients agreed to enroll in this trial, and all underwent treatment. All

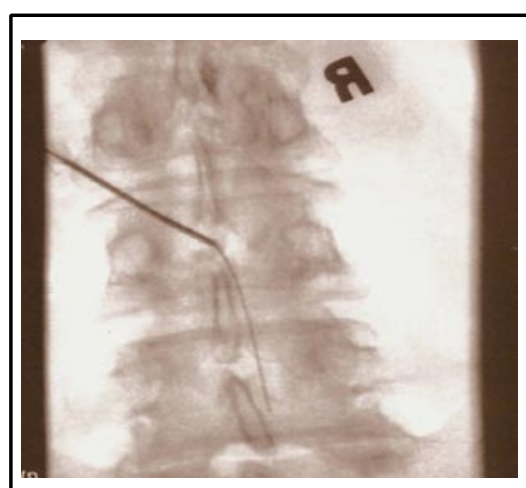

Fig. 1. Anterior-Posterior plain film radiograph, prior to radiopaquecontrastinjection, demonstratingintroducerneedledirected into the right L3-L4 intervertebral space with catheter advanced caudally to treat a right L-5 radiculopathy. 
ten subjects completed the pre-treatment outcome tools and the post-treatment outcome tools at three days and greater than six weeks post procedure. One patient experienced worsening of her symptoms and one remained unchanged, the remaining eight patients experienced improvement of symptoms. The mean pretreatment VAS score was $8.1(\mathrm{SD}=1.2 ; \mathrm{R}$ $=7-10)$. The mean post-treatment VAS score was $4.1(\mathrm{SD}=2.6 ; \mathrm{R}=0.4-8.5)$. The mean change of pain score was $4.1(\mathrm{SD}=$ 2.6; $\mathrm{R}=-9.6-1.5)$. The overall mean improvement based on the VAS score was

49.4\% (Table 1). Subjects exhibited statistically significant improvements in mean VAS pain scores, the eight domains of the SF-36, and Oswestry Disability Scale ( Tables 2 and 3$) t$.

\section{Discussion}

While conducting this study, it was evident that many patients were reluctant to volunteer. Among other factors, it is likely that the ready availability of a known treatment lessened the likelihood of patient participation $(53,27)$. Others (54-55) have reported similar prob-

Table 1. Full analysis of base line outcome measures of patients assigned to undergo treatment

\begin{tabular}{|l|l|}
\hline Pre-treatment Outcome Measures & Mean \pm SD \\
\hline VAS for pain (0-10) & $8.1 \pm 1.2$ \\
\hline SF-36 (0-100) & $23.5 \pm 20.7$ \\
\hline Bodily Pain & $27.5 \pm 23.2$ \\
\hline Physical Functioning & $5.0 \pm 15.8$ \\
\hline Role Physical & $20.0 \pm 35.8$ \\
\hline Role Emotional & $36.3 \pm 26.0$ \\
\hline Social Functioning & $56.8 \pm 20.3$ \\
\hline Mental Health & $51.0 \pm 20.1$ \\
\hline General Health & $25.0 \pm 16.5$ \\
\hline Vitality & $50.1 \pm 10.0$ \\
\hline Oswestry Disability Scale $(0-100)$ & \\
\hline
\end{tabular}

Table 2. Main outcomes of patients who underwent treatment (the $P$ values pertain to paired t-tests)

\begin{tabular}{|c|c|c|c|c|}
\hline $\begin{array}{l}\text { Outcome Measure } \\
(n=10)\end{array}$ & $\begin{array}{c}\text { Pre- } \\
\text { treatment }\end{array}$ & 6 weeks & Change & $\begin{array}{c}P \\
\text { Value }\end{array}$ \\
\hline VAS for pain $(0-10)$ & $8.1 \pm 1.2$ & $4.1 \pm 1.2$ & $4.0 \pm 3.6$ & $<0.01$ \\
\hline $\begin{array}{l}\text { SF-36: Bodily Pain } \\
(0-100)\end{array}$ & $23.5 \pm 20.7$ & $72.5 \pm 16.1$ & $49.0 \pm 27.6$ & $<0.01$ \\
\hline $\begin{array}{l}\text { S F - } 36: \text { P h y s ic a l } \\
\text { Functioning }(0-100)\end{array}$ & $27.5 \pm 23.2$ & $73.9 \pm 15.5$ & $46.4 \pm 28.2$ & $<0.01$ \\
\hline $\begin{array}{l}\text { Oswestry Disability } \\
\text { Scale }(0-100)\end{array}$ & $50.1 \pm 10.0$ & $20.4 \pm 20.0$ & $\begin{array}{c}-29.7 \pm \\
18.6\end{array}$ & $<0.01$ \\
\hline
\end{tabular}

lems when initiating trials of new or controversial treatments for low back or radiculopathy pain. In the present context, epidural injections were readily available from other sources in conventional practice. This limited the population from which the present sample could be drawn. Patients did not need to participate in a trial if they could obtain the treatment elsewhere. Additionally, patients with compensation claims were deliberately excluded in order to avoid potentially confounding effects of litigation. As a result, the sample obtained was not representative of what might be considered the typical patient with chronic low back and radiculopathy pain.

Nevertheless, the sample was appropriate for the nature of this study, which was an explanatory pilot trial to test the technique, in addition to the safety and efficacy, of employing an indwelling epidural catheter and infusion pump to treat radiculopathy. For that purpose, the critical eligibility criterion was that the patients had the correct indication for the procedure, which the present sample satisfied.

Follow-up was achieved at six weeks in $100 \%$ of patients enrolled in the study. Furthermore, since the study was designed as an explanatory study, a six-week followup was judged sufficient to test for statistically significant differences. Six weeks was chosen since it has been shown that after six weeks the results of epidural injections are fairly stable, although six-week outcomes may not be predictive of long-term outcomes.

The principal findings of the study were that the treatment achieved a statistically significant improvement in mean pain scores when compared to the baseline scores. Similarly, SF-36 outcome tools demonstrated improvement.

In this pilot investigation, the epidural catheter and pump technique did not prove to be a universally successful treatment. Twenty percent of the patients did not benefit appreciably, or at all. This feature dilutes mean scores on outcome measures. The incidence of deterioration in pain levels was low.

Each of the ten patients studied had not responded to a regimen of conservative care that included bed-rest, drug therapy, or physical therapy. Two patients had experienced brief significant relief with prior transforaminal injections of lidocaine and corticosteroid, but failed to ex- 
perience sustained relief, yet in the study they experienced appreciable benefit with an indwelling catheter. In this study, one of the subjects of the investigation ultimately underwent a surgical discectomy.

By comparison, in a transforaminal investigation, Weiner and Fraser (56) reported that six of their 30 patients later had surgery. Two of their patients were lost to follow-up but had reported complete relief of their pain at six weeks after injection. Of the remaining 22 patients, 14 had complete relief of pain at an average follow-up of three years (range: 110 years); seven patients had moderate relief of pain. These figures represent a $46 \%$ success rate in achieving complete relief of pain with a transforaminal approach.

Lutz et al (57) reported that 52 of their 69 patients $(75 \%)$ achieved greater than $50 \%$ reduction in their pain, at 28 144 weeks follow-up. They did not report how many patients achieved complete relief of pain.

These and other studies evidence the fact that transforaminal injections don't provide a universal cure for lumbar or sacral radiculopathy pain, but suggest that they constitute a clinically and statistically worthwhile option before embarking on surgery. In those studies, $46 \%$ of patients obtained complete relief, and 75\% of patients obtained greater than 50\% pain, thus precluding their need for surgery (57).

Various factors may account for differences in the outcomes between this pilot trial and other prior studies. The various cohorts may differ in psychosocial domain, the severity of disability, and where they fall within the timeframe of their illness. Additionally, health care providers may express different non-specific effects of treatment, and endorse different selection criteria.

In the present study, one patient subsequently experienced worsening radiculopathy symptoms prior to the six-week endpoint. Closer scrutiny of her MRI which was obtained prior to her treatment, demonstrated a small, extruded disc fragment that was initially unidentified. This criterion could allow the formal exclusion of her participation in this trial, and allow her outcomes to be removed from the group, based on Federal Drug Administration regulations (55). If this one outlier is censored, this changes the mean pain scores at six weeks, improving the mean pain relief and overall strength of this treatment. However, while drawing attention to this possible concession, the authors have chosen not to rely on it for drawing conclusions concerning

Table 3: Pre and Post SF-36 eight domain scores

\begin{tabular}{|c|c|c|c|c|}
\hline $\begin{array}{l}\text { SF-36 } \\
\text { Domains } \\
\text { Measures }\end{array}$ & Baseline & 6 weeks & Change & $P$ Value \\
\hline $\begin{array}{l}\text { Physical } \\
\text { functioning }\end{array}$ & $27.5 \pm 23.2$ & $73.9 \pm 15.5$ & $46.4 \pm 28.2$ & $<0.001$ \\
\hline Role physical & $5.0 \pm 15.8$ & $47.5 \pm 43.2$ & $42.5 \pm 42.6$ & 0.012 \\
\hline $\begin{array}{l}\text { Role } \\
\text { emotional }\end{array}$ & $20.0 \pm 35.8$ & $60.0 \pm 37.8$ & $40.0 \pm 49.2$ & 0.030 \\
\hline Vitality & $25.0 \pm 16.5$ & $67.5 \pm 12.7$ & $42.5 \pm 24.1$ & $<0.001$ \\
\hline Mental health & $56.8 \pm 20.3$ & $82.4 \pm 4.3$ & $25.6 \pm 21.2$ & 0.004 \\
\hline $\begin{array}{l}\text { Social } \\
\text { functioning }\end{array}$ & $36.3 \pm 26.0$ & $79.0 \pm 19.1$ & $42.8 \pm 24.3$ & $<0.001$ \\
\hline Bodily pain & $23.5 \pm 20.7$ & $72.5 \pm 16.1$ & $49.0 \pm 27.6$ & $<0.001$ \\
\hline General health & $51.0 \pm 20.1$ & $75.2 \pm 18.9$ & $24.2 \pm 23.5$ & 0.009 \\
\hline
\end{tabular}

References

1. Robecchi A, Capra R. L'idrocortisone (composto F). Prime esperienze cliniche in campo reumatologico. Minerva Med 1952; 98: 1259-1263.

2. Lievre JA, Bloch-Michel H, Pean G, Uro J. L'hydrocortisone en injection locale. Rev Rhum 1953; 20:310-311.

3. Biella A, Cicognini P. L'acetato di idrocortisone nel trattamento della sindrome sciatalgica. Minerva Med 1954; 1:1863-1865.

4. Cappio M. II trattamento idrocortisonico per via epidurale sacrale delle lombosciatalgie. Reumatismo 1957; 9:60-70.

5. Cappio M, Fragasso V. Osservazioni sull'uso dell'idrocortisone per via epidurale ed endorachidea nelle lombosciatalgie. Riforma Med 1955; 22:605-607.

6. Cappio $M$, Fragasso V. II prednisolone per via epidurale sacrale nelle lombosciatalgie. Reumatismo 1957; 5:905-908.

7. Gerest MF. Le traitement de la nevralgie sciatique par les injections epidurales d'hydrocortisone. J Med Lyon 1958; 261264.

8. Renier JC. L'infitration epidurale par le premier trou sacre posterieur. Revue du Rhu- 
A uthor Affiliation:

Kevin Pauza, MD

Texas Spine and Joint Hospital

1814 Roseland Blvd.

Tyler, TX 75701

E-mail: kevinpauza@tyler.net

Michael Shapiro, MD

Tahoe Spine Center

889 Alder Avenue \#303

Incline Village, NV 89451

E-mail: MikeShapiroMD@aol.com

\section{Aaron Calodney, MD}

Staff Physician

Director and Research Coordinator

Implantable Therapies

NeuroCare Network

P.O. Box 130459

Tyler, TX 75713-0459

E-mail: acmd2001@cs.com

\section{Sejong Bae, PhD}

Assistant Professor

Department of Biostatistics

School of Public Health

University of North Texas

Health Science Center

Fort Worth, TX 76107

\section{Karan P. Singh, PhD}

Full Professor

Department of Biostatistics

School of Public Health

University of North Texas

Health Science Center

Fort Worth, TX 76107

matisme et des Maladies Osteo-articulaire 1959; 26:526-532.

9. Canale L. Il desametazone per via epidurale sacrale nelle lombosciatalgie. Gaz Med Ital 1963; 122:210-213.

10. Gardner WJ, Goebert HW, Sehgal AD. Intraspinal corticosteroids in the treatment of sciatica. Trans Am Neurol Assoc 1961; 86: 214-215.

11. Barry PJC, Kendall PH. Corticosteroid infiltration of the extradural space. Ann Phys Med 1962; 6:267-273.

12. Goebert HW, Jallo SJ, Gardner WJ, Wasmuth CE. Painful radiculopathy treated with epidural injections of procaine and hydrocortisone acetate: results in 113 patients. Anesth Analg 1961; 140:130-134.

13. Hellens A. Lumbar nerve-root compression treated with epidural hydrocortisone. Duodecim 1962; 78:28-31.

14. Lindholm R, Salenius P. Caudal, epidural administration of anaesthetics and corti- coids in the treatment of low back pain. Acta Orthop Scand 1964; 1:114-116.

15. Mahner A. Die peridurale Injektion von Novocain und Kortikosteroiden in der Therapie des lumbalen radikularen Syndrom. Zbl Chir 1960; 85:625-635.

16. Derby R, Kine G, Saal J, Reynolds J, Goldthwaite N, White A, Hsu K, Zucherman J. Response to steroid and duration of radicular pain as predictors of surgical outcome. Spine 1992; 17:S176-S183.

17. Derby R, Bogduk N, Kine G. Precision percutaneous blocking procedures for localizing spinal pain. Part 2. The lumbar neuraxial compartment. Pain Digest 1993; 3:175188.

18. Bogduk N. Spine update: epidural steroids. Spine 1995; 20:845-848.

19. Bogduk N, Aprill C, Derby R. Epidural steroid injections. In White $\mathrm{AH}$ (ed.) Spine Care, Volume One: Diagnosis and Conservative Treatment Mosby, St. Louis, 1995, pp 322-343.

20. Riew KD, Yin Y, Gilula L, Bridwell KH, Lenke LG, Lauryssen C, Goette K. The effect of nerve-root injections on the need for operative treatment of lumbar radicular pain. $A$ prospective, randomized, controlled, double-blind study. J Bone Joint Surg 2000; 82A:1589-1593.

21. Karppinen J, Malmivaara A, Kurunlahti $M$, Kyllonen E, Pienimaki T, Niemenen P, Ohinmaa A, Tervonen O, Vanharanta $\mathrm{H}$. Periradicular infiltration for sciatica. A randomized controlled trial. Spine 2001; 26:10591067.

22. Karppinen J, Ohinmaa A, Malmivaara A Kurunlahti M, Kyllonen E, Pienimaki T, Niemenen $\mathrm{P}$, Tervonen $\mathrm{O}$, Vanharanta $\mathrm{H}$. Cost-effectiveness of periradicular infiltration for sciatica. Subgroup analysis of a randomized controlled trial. Spine 2001; 26:2587-2595.

23. Vad VB, Bhat AL, Lutz GE, Cammisa F. Transforaminal epidural steroid injections in lumbosacral radiculopathy. Spine 2002; 27:11-16

24. Bogduk N, Christophidis N, Cherry D. Epidural use of steroids in the management of back pain and sciatica of spinal origin. Report of the Working Party on Epidural use of Steroids in the Management of Back Pain. National Health and Medical Research Council, Canberra, 1993.

25. Benzon HT. Epidural steroid injections for low back pain and lumbosacral radiculopathy. Pain 1986; 24:277-295.

26. Kepes ER, Duncalf D. Treatment of backache with spinal injections of local anesthetics, spinal and systemic steroids: A review. Pain 1985; 22:33-47.

27. Koes BW, Scholten RJPM, Mens JM, Bouter LM. Efficacy of epidural steroid injections for low back pain and sciatica: a systematic review of randomized clinical trials. Pain 1995; 63:279-288.

28. Olmarker K, Rydevik B, Holm S. Edema formation in spinal nerve roots induced by experimental, graded compression: an ex- perimental study on the pig cauda equina with special reference to differences in effects between rapid and slow onset of compression. Spine 1989; 14:569-573.

29. Yoshizawa H, Nakai S, Koboyashi S, Morita T, Shizu N. Intraradicular edema formation as a basic factor in lumbar radiculopathy. Weinstein JN, Gordon SL (eds). Low Back Pain: A Scientific and Clinical Overview. American Academy of Orthopaedic Surgeons. Rosemont, IL, 1996, pp 235-246.

30. Olmarker K. Mechanical and biochemical injury of spinal nerve roots: an experimental perspective. In Weinstein JN, Gordon SL (eds). Low Back Pain: A Scientific and Clinical Overview. American Academy of Orthopaedic Surgeons, Rosemont, IL, 1996, pp 215-233.

31. Olmarker K, Rydevik B, Holm B, Bagge U. Effects of experimental graded compression on blood flow in spinal nerve roots: a vital microscopic study on the porcine cauda equina. J Orthop Res 1989; 7:817-823.

32. Bobechko WT, Hirsch C. Autoimmune response to nucleus pulposus in the rabbit. J Bone Joint Surg 1965; 47B:574-580.

33. Elves MW, Bucknill T, Sullivan MF. In vitro inhibition of leucocyte migration in patients with intervertebral disc lesions. Orthop Clin North Am 1975; 6:59-65.

34. Gertzbein SD. Degenerative disk disease of the lumbar spine: immunological implications. Clin Orthop 1977; 129:68-71.

35. Gertzbein SD, Tait JH, Devlin SR. The stimulation of lymphocytes by nucleus pulposus in patients with degenerative disk disease of the lumbar spine. Clin Orthop 1977; 123:149-154.

36. Gertzbein SD, Tile M, Gross A, Falk R. Autoimmunity in degenerative disc disease of the lumbar spine. Orthop Clin North Am 1975; 6:67-73.

37. McCarron RF, Wimpee MW, Hudkins PG, Laros GS. The inflammatory effect of nucleus pulposus: a possible element in the pathogenesis of low-back pain. Spine 1987; 12:760-764.

38. Olmarker K, Blomquist J, Stromberg J, Nanmark U, Thomsen P, Rydevik B. Inflammatogenic properties of nucleus pulposus. Spine 1995; 20:665-669.

39. Kang JD, Geirgescu HI, Mclntyre-Larkin L, Stefanovic-Racic M, Donaldson III WF, Evans $\mathrm{CH}$. Herniated lumbar intervertebral discs make neutral metalloproteases, nitric oxide, and interleukin-6. Orthop Trans 1995; 19:53.

40. Cavanaugh JM, Ozaktay AC, Vaidyanathan S. Mechano- and chemosensitivity of lumbar dorsal roots and dorsal root ganglia: an in vitro study. Trans Orthop Res Soc 1994; 19:109-112.

41. Olmarker K, Byrod G, Cornefjord M, Nordborg, Rydevik B. Effects of methylprednisolone on nucleus pulposus-induced nerve root injury. Spine 1994; 19:1803-1808.

42. Kawakami M, Weinstein JN, Tamaki T, Hashizue $H$. The difference in nociceptive potential of the nucleus pulposus and 
the anulus fibrosus. In Weinstein JN, Gordon SL (eds). Low Back Pain: A Scientific and Clinical Overview. American Academy of Orthopaedic Surgeons, Rosemont, IL, 1996, pp 209-213.

43. Kawakami $M$, Tamaki $T$, Weinstein $\mathrm{JN}$, Hashizume $\mathrm{H}$, Nishi $\mathrm{H}$, Meller ST. Pathomechanism of pain-related behavior produced by allografts of intervertebral disc in the rat. Spine 1996; 21:21012107.

44. Merskey H, Bogduk N (eds). Classification of Chronic Pain. Descriptions of Chronic Pain Syndromes and Definition of Pain Terms, $2^{\text {nd }}$ ed. IASP Press, Seattle, 1994.

45. Huskisson EC. Measurement of pain. Lancet 1974; 2:1127-1131.

46. Price DD, McGrath PA, Rafii A, Buckingham $B$. The validation of visual analogue scales as ratio scale measures for chronic and experimental pain. Pain 1983; 17:45-56.

47. Carlsson AM. Assessment of chronic pain. I. Aspects of the reliability and validity of the visual analogue scale. Pain 1983; 16: 87-101.

48. Chapman CR, Casey KL, Dubner R, Foley KM, Gracely RH, Reading AE. Pain measurement: An overview. Pain 1985; 22:1-31.

49. Ware JE, Sherbourne CD. The MOS 36-Item Short-Form Health Survey (SF-36): I. Conceptual framework and item selection. Medical Care 1992; 30:473-483.

50. McHornery CA, Ware JE, Rogers WH, Raczek $A E$, Lu JFR. The validity and relative precision of MOS Short-and Long-Form Health Status Scales and Dartmouth COOP charts: results from Medical Outcomes Study. Medical Care 1992; 30:MS 253-MS 265.

51. McHornery CA, Ware JE, Raczek AE. The MOS 36-Item Short-Form Health Survey (SF-36): II. Psychometric and clinical tests of validity in measuring physical and mental health constructs. Medical Care 1993; 31:247-263.

52. Fairbank JCT, Couper J, Davies JB, O'Brien
JP. The Oswestry low back pain disability questionnaire. Physiotherapy 1980; 72:7174

53. Koes BW, Scholten RJPM, Mens JMA, Bouter LM. Efficacy of non-steroidal anti-inflammatory drugs for low back pain: a systematic review of randomized clinical trials. Ann Rheum Dis 1997; 56:214-223.

54. Hopwood MB, Manning DEC. Lumbar epidural steroid injections: is a clinical trial necessary or appropriate. Reg Anesth Pain Med 1999; 24:5-7

55. Federal Register, Volume 63, No. 179, Docket No. 97D-0174 "E9 Statistical Principles for Clinical Trials", Section 5.3 "Missing Values and Outliers", p 49594.

56. Weiner BK, Fraser RD. Foraminal injection for lateral lumbar disc herniation. J Bone Joint Surg 1997; 79B:804-807

57. Lutz GE, Vad VB, Wisneski RJ. Flouroscopic transforaminal lumbar epidural steroids: an outcome study. Arch Phys Med Rehabili 1998; 79:1362-1366. 